\title{
Physical Activity in Youth Dance Classes
}

Kelli L. Cain, MA ${ }^{a, b}$, Kavita A. Gavand, MS ${ }^{b}$, Terry L. Conway, PhD ${ }^{b, c}$, Emma Peck, BA ${ }^{a}$, Nicole L. Bracy, PhD ${ }^{a, b}$, Edith Bonilla, BA ${ }^{a, b}$, Patricia Rincon, MFA', James F. Sallis, $\mathrm{PhD}^{\mathrm{a}, \mathrm{b}}$

BACKGRound AND OBJECTIVES: The majority of youth are not meeting the US Department of Health and Human Services physical activity guidelines. Dance is a popular activity, particularly for girls, and has the potential to increase physical activity for many youth. This study investigated physical activity of children and adolescents in 7 dance types: ballet, hip-hop, jazz, Latinflamenco, Latin-salsa/ballet folklorico, partnered, and tap.

мEтHODS: Data were collected in 17 private studios and 4 community centers in San Diego, California. A total of 264 girls from 66 classes participated $(n=154$ children; $n=110$ adolescents). Physical activity was measured with accelerometers, and activity levels during class were calculated.

RESULTS: Participants recorded an average of $17.2 \pm 8.9$ minutes of moderate-to-vigorous physical activity (36\% of class), but this varied by age and dance type. For children, dance type differences were observed with percent of class in moderate-to-vigorous physical activity ranging from $13.6 \%$ (Latin-flamenco) to $57 \%$ (hip-hop). For adolescents, there were no differences across dance types. Children were more active than adolescents in all types except ballet. Children and adolescents were more active in private compared with community center classes.

concLusıons: Overall, physical activity in youth dance classes was low; $8 \%$ of children and $6 \%$ of adolescents met the Centers for Disease Control and Prevention 30-minute guideline for afterschool physical activity during dance. To increase physical activity in dance classes, teaching methods could be employed to increase activity in all types, or emphasis could be placed on greater participation in more active dance types.

WHAT'S KNOWN ON THIS SUBJECT: The majority of youth are not meeting the recommended physical activity guidelines. Dance classes are popular for girls and have potential to provide physical activity for many youth. Little is known about how active youth are in different dance types.

WHAT THIS STUDY ADDS: Objectively measured physical activity in dance classes are low and generally provide less physical activity than youth sports. There is a public health imperative to engage the dance profession in efforts to improve the health impact of youth dance classes.
Department of ${ }^{a}$ Psychology and ${ }^{C}$ Graduate School of Public Health, San Diego State University Research Foundation, San Diego, California; and Departments of ${ }^{b}$ Family and Preventive Medicine and ${ }^{d}$ Theatre and Dance, University California San Diego, La Jolla, California

Ms Cain conceptualized and designed the study, participated in data management and analyses, and drafted parts of the manuscript; Ms Gavand carried out the final analyses and drafted parts of the manuscript; Dr Conway participated in study design, consulted on analyses and interpretation, and critically reviewed and revised the manuscript; Ms Peck participated in study design, data collection, initial analyses and interpretation, and drafted parts of the manuscript; Dr Bracy participated in study design, data management, initial analyses and interpretation, and critically reviewed and revised the manuscript; Ms Bonilla participated in study design, coordinated data collection, participated in data management and results interpretation, and critically reviewed and revised the manuscript; Ms Rincon participated in study design, results interpretation and critically reviewed and revised the manuscript; Dr Sallis conceptualized the study, participated in study design, and critically reviewed and revised the manuscript; and all authors approved the final manuscript as submitted.

www.pediatrics.org/cgi/doi/10.1542/peds.2014-2415

DOI: 10.1542/peds.2014-2415

Accepted for publication Mar 18, 2015 
Children and adolescents are recommended to accumulate at least 60 minutes of moderate-to-vigorous physical activity (MVPA) most days, ${ }^{1}$ because of its multiple physical and mental health benefits. ${ }^{2}$ However, data based on objective measures with accelerometers reveal $42 \%$ of children and $8 \%$ of adolescents are meeting these guidelines. ${ }^{3}$ The Centers for Disease Control and Prevention recommends that schools provide 30 minutes of MVPA per day, with after-school activities providing the remaining 30 minutes. ${ }^{4}$

Most physical activity among adolescents occurs after school in organized and structured programs such as sports teams and dance lessons. ${ }^{5}$ Dance is particularly popular among girls, ${ }^{6,7}$ which means it has the potential to reduce the welldocumented gender differential in youth physical activity. ${ }^{8}$ Dance has many health benefits such as muscle and bone strengthening, increased flexibility, improvements in balance and spatial awareness, and enhanced cognitive functioning. Dance can contribute to an overall healthy lifestyle and can also provide an opportunity for social interaction.9,10 Dance is commonly taught in schools and community-based dance studios. The National Dance Education Association estimates that $43 \%$ of youth in the United States obtain dance instruction at schools, most often during physical education. An unknown number of US youth take classes in more than 30000 dance studios. ${ }^{11}$ Dance has the potential to contribute to a healthy lifestyle and overall MVPA. Among female youth who reported dancing, almost $40 \%$ of their total MVPA was attributable to dance. ${ }^{7}$ Another study revealed that girls obtained 70\% more MVPA and $8 \%$ less sedentary time on days they attended dance classes. ${ }^{12}$

There are numerous dance styles that vary in amount and intensity of physical activity. $0^{\prime} \mathrm{Neill}$ et $\mathrm{al}^{13}$ found that adolescent jazz/tap classes provided more MVPA compared with ballet $(19.6 \%$ vs $12.5 \%$ of class time, respectively). Nelson et $\mathrm{al}^{14}$ found that swing, fun dance, and merengue generated higher heart rates compared with foxtrot, waltz, and tango in a fifth grade school-based dance program. Huang et $\mathrm{al}^{15}$ found that ballroom/partnered dances such as swing, merengue, tango, and foxtrot promoted MVPA during at least $50 \%$ of the class time in 9- to 11-year-old children. However, several popular dance types such as hip-hop, flamenco, and salsa have not been evaluated. If it is confirmed that specific dance types are found to be particularly good sources of physical activity for children and adolescents, more active dance types can be recommended for school and community programs as a means of increasing youth physical activity, particularly among girls.

The current study aimed to investigate the physical activity of children and adolescents in 7 general types of studio dance classes including: ballet, jazz, hip-hop, Latinflamenco (Latin-F), Latin-salsa and ballet folklorico (Latin-SBF), tap, and partnered dance (which included ballroom, merengue, and swing). Because fees can be a barrier to participation among youth from lowincome families, dance classes in fullfee private and reduced-fee or free community center studios were contrasted to assess whether the setting was associated with physical activity during dance classes.

\section{METHODS}

\section{Recruitment}

Five hundred fifty-one private and public dance studios in San Diego County, California, were identified from online business directories. Eligible studios offered group classes in at least 1 of the dance types of interest. Dance types were selected to represent a broad range of commonly taught styles. Two hundred eightyseven studios did not meet these criteria, and 54 were closed. From the list of 210 eligible studios, contacts were made in a random order until 4 community centers and 17 private studios agreed to participate. Ten studios declined to participate in the study. Community centers were recruited to assess dance classes available to lower income youth.

After obtaining permission from the dance studios, research staff visited individual dance instructors to explain the study and get permission to collect data in their classes, which included both the teacher and students wearing an accelerometer for the length of the class and completing a brief survey. Only beginner and intermediate level classes were eligible. Research assistants then visited classes to solicit interest among students to participate. Students had to be girls between 5 and 18 years old, willing to wear an accelerometer during the entire dance lesson, and be participating in the study for the first time (ie, have not participated in the study during a different dance class). Although data were collected from girls and boys, few participants were boys. Thus, only girls were included in analyses. Parental consent and child assent were obtained, and the study protocol was approved by the San Diego State University Institutional Review Board.

\section{Dance Class Characteristics}

Research staff observed each dance lesson and recorded the number of girls present for the class (ie, class size, which included both study participants and nonparticipants), and the start and end time of each lesson to compute class length (minutes).

\section{Student Characteristics}

Parents reported their child's age, gender, and race/ethnicity (coded as white non-Hispanic versus other). Parents also reported their child's height and weight, and BMI was calculated $\left(\mathrm{kg} / \mathrm{m}^{2}\right)$. BMI percentiles 
were calculated by using age- and gender-specific guidelines. ${ }^{16}$

\section{Dance Instructor Characteristics}

Dance instructors reported their age, gender, race/ethnicity (coded as white non-Hispanic versus other), and years of experience teaching dance.

\section{Physical Activity}

Each participant and dance instructor was fitted with a waist-worn Actigraph GT3 $\times$ accelerometer before the dance lesson. Accelerometers have been validated for objectively assessing physical activity in youth and are widely

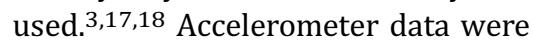
collected at 15-second epochs by using the normal filter and scored using Freedson 3 Metabolic Equivalent of Task (MET) age-specific cut points for youth and Freedson Adult cut points for instructors. ${ }^{19,20}$ Sedentary behavior was defined as $\leq 100 \mathrm{cpm}^{21,22}$ The exact start and end times of class that were recorded by research assistants were used to eliminate all nonclass time from the accelerometer data. MeterPlus version 4.3 (www.meterplussoftware. com) was used to summarize minutes of sedentary, light, moderate, vigorous, and MVPA (moderate + vigorous) during dance classes. Total time (minutes) and percent of class time (minutes divided by class length) spent in each intensity level were calculated.

\section{Statistical Analysis}

SPSS version 21.0 (IBM SPSS

Statistics, IBM Corporation) was used for analyses. Descriptives for participant, class, and instructor characteristics were summarized for each dance type by 2 age groups: children (5-10 years old) and adolescents (11-18 years old). Mixed linear regression analyses were performed to assess the effect of dance types on the various physical activity outcomes for children and adolescents separately, adjusting for covariates as fixed effects and instructor and dance class as random effects to account for participant clustering of students within classes and classes within instructors. Hiphop was set as the reference group. To identify covariates to include in the models, Spearman's correlations were performed with each of the student and teacher variables and physical activity outcomes. Variables with significant correlations $(P<.05)$ with at least 1 physical activity outcome were included as covariates in all models. Covariates included in the models were student's age, race/ ethnicity (non-Hispanic/white or other), class length (for "total time" outcomes), BMI percentile, instructors' MVPA (minutes), and whether the class was private or community based. All dance types were represented in both private and community-based settings, with the exception of partnered and Latin-SBF, which were only found in private studios.

\section{RESULTS}

A total of 264 girls participated in the study ( $n=154$ children and $n=110$ adolescents). Descriptive characteristics are presented in Tables 1 and 2. Mean age was $7.8 \pm$ 1.5 and $13.1 \pm 1.9$ for children and adolescents, respectively. The majority of participants were nonHispanic/white $(67.1 \%$ and $71.6 \%$ of children and adolescents, respectively). The highest percent of overweight/obese children were found in partnered dance (40\%) with the lowest in tap (16\%). The highest percent of overweight/obese adolescents were found in Latin-SBF classes $(50 \%)$ with the lowest in ballet $(0 \%)$.

Covariate-adjusted means for activity outcomes are presented in Table 3, along with results from the mixed model linear regressions investigating the statistical significance of differences between dance types for sedentary, light, moderate, vigorous, and MVPA. For children, significant differences were observed by dance type in all activity categories with the strongest differences found with

TABLE 1 Student, Class, and Instructor Characteristics by Dance Class Type in Children

\begin{tabular}{|c|c|c|c|c|c|c|c|c|}
\hline & All Classes & Latin-F & Latin-SBF & Ballet & Tap & Jazz & Partnered Dance & Hip-Hop \\
\hline Students & $n=154$ & $n=16$ & $n=19$ & $n=27$ & $n=29$ & $n=20$ & $n=10$ & $n=33$ \\
\hline Age & $7.8(1.5)$ & $7.6(1.3)$ & $8.0(1.6)$ & $7.3(1.8)$ & $7.9(1.5)$ & $8.1(1.4)$ & $7.5(1.4)$ & $7.9(1.4)$ \\
\hline Non-Hispanic/white, \% & 67.1 & 26.7 & 33.3 & 55.6 & 82.8 & 95.0 & 80.0 & 78.8 \\
\hline BMI percentile & $0.5(0.3)$ & $0.5(0.4)$ & $0.6(0.3)$ & $0.6(0.4)$ & $0.3(0.3)$ & $0.6(0.3)$ & $0.5(0.4)$ & $0.6(0.4)$ \\
\hline Overweight/obese, \% & 27.3 & 30.8 & 31.6 & 36.4 & 16.0 & 20.0 & 40.0 & 26.7 \\
\hline Classes & $n=33$ & $n=3$ & $n=3$ & $n=7$ & $n=7$ & $n=3$ & $n=3$ & $n=7$ \\
\hline Class size ${ }^{a}$ & $9.1(4.9)$ & $9.3(4.0)$ & $9.3(3.5)$ & $6.7(3.8)$ & $9.3(6.7)$ & $10.0(4.4)$ & $11.0(8.7)$ & $10.1(4.4)$ \\
\hline Class length, min & $48.3(7.6)$ & $49.7(1.2)$ & $53.8(6.9)$ & $49.2(5.6)$ & $45.0(7.9)$ & $39.0(1.7)$ & $53.2(9.6)$ & $49.7(9.0)$ \\
\hline Instructors & $n=33$ & $n=3$ & $n=3$ & $n=7$ & $n=7$ & $n=3$ & $n=3$ & $n=7$ \\
\hline Age & $32.2(11.4)$ & $52.0(17.3)$ & $45.0(9.5)$ & $28.0(8.4)$ & $30.3(8.0)$ & $31.7(10.6)$ & $30.7(3.5)$ & $25.1(5.5)$ \\
\hline Women, \% & 87.9 & 100.0 & 100.0 & 100.0 & 85.7 & 100.0 & 66.7 & 71.4 \\
\hline Non-Hispanic/white, \% & 62.5 & 33.3 & 100.0 & 71.4 & 71.4 & 50.0 & 66.7 & 85.7 \\
\hline Experience, y & $12.9(11.1)$ & $25.0(21.7)$ & $31.3(10.3)$ & $8.8(7.7)$ & $8.9(5.7)$ & $8.1(8.1)$ & $16.7(2.9)$ & $8.2(4.9)$ \\
\hline MVPA, min & $5.6(6.5)$ & $1.0(1.7)$ & $4.2(5.2)$ & $2.6(2.0)$ & $3.7(2.5)$ & $9.8(5.3)$ & $2.2(3.3)$ & $12.9(9.2)$ \\
\hline
\end{tabular}

Data are presented as mean (SD) or percent unless noted otherwise.

a Total number of students attending class; includes study participants plus nonparticipants. 
TABLE 2 Student, Class, and Instructor Characteristics by Dance Class Type in Adolescents

\begin{tabular}{|c|c|c|c|c|c|c|c|c|}
\hline & All Classes & Latin- $\mathrm{F}$ & Latin-SBF & Ballet & Tap & Jazz & Partnered Dance & Hip-Нор \\
\hline Students & $n=110$ & $n=12$ & $n=6$ & $n=23$ & $n=19$ & $n=18$ & $n=9$ & $n=23$ \\
\hline Age & $13.1(1.9)$ & $11.7(0.9)$ & $12.0(2.0)$ & $14.0(1.7)$ & $13.6(2.3)$ & $12.8(1.9)$ & $13.1(1.7)$ & $13.0(1.8)$ \\
\hline Non-Hispanic/white, \% & 71.6 & 41.7 & 83.3 & 78.3 & 68.4 & 88.9 & 77.8 & 63.6 \\
\hline BMI percentile & $0.5(0.3)$ & $0.6(0.3)$ & $0.6(0.5)$ & $0.4(0.3)$ & $0.5(0.3)$ & $0.6(0.3)$ & $0.5(0.3)$ & $0.5(0.3)$ \\
\hline Overweight/obese, \% & 18.1 & 33.3 & 50.0 & 0.0 & 16.7 & 20.0 & 11.1 & 22.7 \\
\hline Classes & $n=33$ & $n=4$ & $n=3$ & $n=5$ & $n=6$ & $n=3$ & $n=4$ & $n=8$ \\
\hline Class size $\mathrm{a}^{\mathrm{a}}$ & $8.5(5.0)$ & $5.3(2.9)$ & $9.7(3.1)$ & $7.2(3.9)$ & $9.0(6.6)$ & $9.8(3.3)$ & $11.3(6.9)$ & $8.3(6.1)$ \\
\hline Class length, min & $50.2(11.6)$ & $43.8(6.4)$ & $52.7(6.5)$ & $55.2(15.0)$ & $46.2(8.7)$ & $43.5(11.3)$ & $61.5(16.4)$ & $50.2(9.5)$ \\
\hline Instructors & $n=33$ & $n=4$ & $n=3$ & $n=5$ & $n=6$ & $n=3$ & $n=4$ & $n=8$ \\
\hline Age & $34.5(13.4)$ & $46.0(18.6)$ & $45.0(9.5)$ & $35.4(11.4)$ & 36.5 (19.5) & $31.0(8.8)$ & $32.5(4.7)$ & $24.4(5.0)$ \\
\hline Women, \% & 84.8 & 100.0 & 100.0 & 80.0 & 100.0 & 100.0 & 50.0 & 71.4 \\
\hline Non-Hispanic/white, \% & 56.3 & 25.0 & 100.0 & 60.0 & 83.3 & 66.7 & 75.0 & 57.1 \\
\hline Experience, y & $15.2(13.5)$ & $20.0(20.3)$ & $31.3(10.3)$ & $14.8(9.4)$ & $17.9(20.3)$ & $9.9(7.5)$ & $16.3(2.5)$ & $6.1(4.8)$ \\
\hline MVPA, $\min$ & $5.6(6.2)$ & $0.0(0.0)$ & $3.7(5.5)$ & $5.6(5.9)$ & $3.5(3.4)$ & $10.0(4.1)$ & $2.0(2.7)$ & $11.1(8.0)$ \\
\hline
\end{tabular}

Data are presented as mean (SD) or percent unless noted otherwise.

a Total number of students attending class; includes study participants plus nonparticipants.

percent of class time spent in MVPA $(F=6.4, P<.001)$, which ranged from $13.6 \%$ in Latin-F to $57 \%$ in hiphop classes. For adolescents, there were no significant overall differences across dance types in any activity category. As can be seen in Table 3, the ranges of means across dance types for all activity categories were much narrower for adolescents than for children.

Hip-hop classes provided the least amount of sedentary time
(9.1 minutes; $18.5 \%$ of class time) and the most MVPA (26.9 minutes; $57 \%$ of class time) for children, whereas ballet provided the most MVPA for adolescents (16.6 minutes; $31 \%$ of class time). Latin-SBF classes were the least sedentary for adolescents (9.9 minutes; $17.3 \%$ of class time). Latin-F classes were the most sedentary for children and adolescents (26.9 minutes; $55 \%$ of class time and 23.2 minutes; $43.8 \%$ of class time, respectively) and provided the least amount of MVPA (6 minutes; $13.6 \%$ of class time and 4 minutes; $6.7 \%$ of class time, respectively) compared with other dance types.

Descriptive characteristics of the sample for private and community center classes are presented in Table 4. Private classes had a higher percent of overweight/obese children and adolescents (30.4\% and 21.9\%, respectively) compared with community centers $(21.3 \%$ and $9.4 \%)$.

TABLE 3 Relationship of Sedentary, Light, Moderate, Vigorous, and Moderate-to-Vigorous Intensity Physical Activity With Dance Class Type

\begin{tabular}{|c|c|c|c|c|c|c|c|c|c|c|}
\hline & \multicolumn{5}{|c|}{ Minutes } & \multicolumn{5}{|c|}{ Percent of Class Time } \\
\hline & $\begin{array}{l}\text { Sedentary } \\
\left(_{(M i n)^{a}}\right.\end{array}$ & $\begin{array}{l}\text { Light } \\
\left(_{\text {Min })^{a}}\right.\end{array}$ & $\begin{array}{l}\text { Moderate } \\
(\text { Min })^{a}\end{array}$ & $\begin{array}{l}\text { Vigorous } \\
\left(_{\text {Min })^{a}}\right.\end{array}$ & $\begin{array}{l}\text { MVPA } \\
(\operatorname{Min})^{\text {a }}\end{array}$ & $\begin{array}{l}\text { Sedentary } \\
(\% \text { Time })^{\mathrm{b}}\end{array}$ & $\begin{array}{c}\text { Light } \\
(\% \text { Time })^{\mathrm{b}}\end{array}$ & $\begin{array}{l}\text { Moderate } \\
\left(\% \text { Time }^{\mathrm{b}}\right.\end{array}$ & $\begin{array}{l}\text { Vigorous } \\
\left(\% \text { Time }^{\mathrm{b}}\right.\end{array}$ & $\begin{array}{c}\text { MVPA } \\
(\% \text { Time })^{\mathrm{b}}\end{array}$ \\
\hline \multicolumn{11}{|l|}{ Children } \\
\hline Overall $F$ dance type & $6.62^{\star \star \star}$ & $2.77^{\star}$ & $6.46^{\star \star \star}$ & 2.06 & $5.60^{\star \star \star}$ & $6.48^{\star \star \star}$ & $3.36^{*}$ & $6.25^{\star \star \star}$ & $2.88^{*}$ & $6.42^{\star \star \star}$ \\
\hline Ballet & $15.0(1.7)^{\star}$ & $19.0(1.6)^{\star \star}$ & $11.6(1.5)^{\star \star}$ & $2.2(1.4)^{\star \star}$ & $13.9(2.1)^{\star \star \star}$ & $30.9(3.5)^{*}$ & $39.6(2.9)^{\star \star \star}$ & $25.0(3.2)^{\star \star}$ & $4.5(2.5)^{\star \star}$ & $29.5(4.2)^{\star \star \star}$ \\
\hline Partnered & $11.2(2.3)$ & $14.2(2.0)$ & $15.3(2.1)$ & $6.2(1.8)$ & $22.3(2.9)$ & $22.5(4.8)$ & $29.5(3.8)$ & $33.4(4.3)$ & $13.4(3.3)$ & $47.5(5.7)$ \\
\hline Latin-SBF & $11.1(2.2)$ & $16.2(1.9)$ & $16.8(1.9)$ & $3.2(1.8)$ & $18.1(2.8)^{\star}$ & $23.2(4.5)$ & $34.6(3.6)^{*}$ & $35.5(4.1)$ & $5.3(3.2)^{\star}$ & $39.0(5.3)^{*}$ \\
\hline Latin-F & $26.9(2.5)^{\star \star \star}$ & $14.2(2.2)$ & $3.6(2.3)^{\star \star \star}$ & $2.3(2.0)$ & $6.0(3.2)^{\star \star \star}$ & $55.0(5.2)^{\star \star \star}$ & $30.7(4.1)$ & $8.7(4.7)^{\star \star \star}$ & $4.9(3.6)^{\star}$ & $13.6(6.2)^{\star \star \star}$ \\
\hline Tap & $13.1(1.6)$ & $15.8(1.3)^{*}$ & $15.9(1.5)$ & $3.5(1.2)^{\star}$ & $19.2(2.1)^{\star}$ & $27.3(3.4)$ & $33.1(2.4)^{\star}$ & $33.4(3.1)$ & $7.0(2.2)^{\star}$ & $40.3(4.0)^{\star \star}$ \\
\hline Jazz & $11.4(2.2)$ & $13.5(1.6)$ & $16.1(1.9)$ & $5.9(1.5)$ & $22.1(2.7)$ & $23.0(4.5)$ & $27.1(3.2)$ & $34.5(4.1)$ & $13.5(2.9)$ & $48.4(5.3)$ \\
\hline Hip-hop & $9.1(1.7)$ & $11.9(1.6)$ & $19.5(1.5)$ & $7.3(1.4)$ & $26.9(2.2)$ & $18.5(3.6)$ & $23.8(3.0)$ & $41.6(3.2)$ & $15.4(2.6)$ & $57.0(4.2)$ \\
\hline \multicolumn{11}{|l|}{ Adolescents } \\
\hline Overall $F$ dance type & 2.14 & 1.62 & 1.98 & 1.18 & 1.67 & 2.22 & 1.68 & 2.09 & 1.7 & 1.75 \\
\hline Ballet & $17.0(2.6)$ & $21.6(2.0)$ & $11.9(1.8)$ & $4.1(1.3)$ & $16.6(2.8)$ & $31.4(5.0)$ & $41.7(3.8)$ & $22.7(3.6)$ & $8.3(2.4)$ & $31.0(5.1)$ \\
\hline Partnered & $15.5(4.1)$ & $30.5(3.2)$ & $8.8(2.8)$ & $-0.1(2.0)$ & $9.3(4.1)$ & $26.8(8.0)$ & $54.5(6.1)$ & $21.7(5.4)$ & $1.5(3.6)$ & $23.2(7.6)$ \\
\hline Latin-SBF & $9.9(4.0)$ & $28.8(3.1)$ & $11.3(2.7)$ & $0.4(1.9)$ & $11.2(3.9)$ & $17.3(7.8)$ & $53.5(5.9)$ & $21.2(5.1)$ & $-0.2(3.5)$ & $23.9(7.3)$ \\
\hline Latin-F & $23.2(3.8)$ & $25.0(2.8)$ & $4.1(2.3)$ & $0.1(1.7)$ & $4.0(3.4)$ & $43.8(7.3)$ & $48.0(5.5)$ & $7.2(4.5)$ & $-0.9(3.0)$ & $6.7(6.5)$ \\
\hline Tap & $15.6(2.5)$ & 23.7 (1.9) & $9.6(1.8)$ & $3.4(1.3)$ & $12.7(2.7)$ & $27.5(4.9)$ & $44.2(3.7)$ & $18.8(3.5)$ & $6.6(2.4)$ & $26.0(5.0)$ \\
\hline Jazz & $16.9(3.0)$ & $21.0(2.3)$ & $11.0(2.3)$ & $3.2(1.6)$ & $13.9(3.5)$ & $29.9(5.8)$ & $37.5(4.5)$ & $22.6(4.5)$ & $6.9(3.0)$ & $30.2(6.3)$ \\
\hline Hip-hop & $12.4(2.5)$ & $24.1(1.9)$ & $14.0(1.9)$ & $2.1(1.3)$ & $15.6(2.8)$ & $22.3(4.8)$ & $46.4(3.7)$ & $27.3(3.6)$ & $3.0(2.4)$ & $30.6(5.2)$ \\
\hline
\end{tabular}

$\star P \leq .05 ;{ }^{* *} P \leq .01 ; * \star P \leq .001$.

a Analyses adjusted for age, race, class length, BMI percentile, instructor MVPA, community versus private, and clustering within dance classes and instructors.

b Analyses adjusted for age, race, BMI percentile, instructor MVPA, community versus private, and clustering within dance classes and instructors.

c Reference group is hip-hop. 
TABLE 4 Student, Class, and Instructor Characteristics by Private and Public Dance Classes in Children and Adolescents

\begin{tabular}{lccccc}
\hline & \multicolumn{2}{c}{ Children } & & \multicolumn{2}{c}{ Adolescents } \\
\cline { 2 - 3 } \cline { 5 - 6 } & Private & Community & & Private & Community \\
\hline Students & $n=103$ & $n=51$ & $n=76$ & $n=34$ \\
Age & $7.8(1.6)$ & $7.8(1.4)$ & & $12.9(2.0)$ & $13.5(1.7)$ \\
Non-Hispanic/white, \% & 61.4 & 78.4 & & 73.3 & 67.6 \\
BMl percentile & $0.6(0.3)$ & $0.5(0.4)$ & & $0.6(0.3)$ & $0.5(0.3)$ \\
Overweight/obese, \% & 30.4 & 21.3 & & 21.9 & 9.4 \\
Classes & $n=26$ & $n=7$ & & $n=25$ & $n=8$ \\
Class size & $7.8(4.6)$ & $13.9(2.8)$ & & $7.6(4.6)$ & $11.6(5.4)$ \\
Class length, min & $50.5(7.1)$ & $40.3(2.4)$ & & $51.8(10.4)$ & $45.3(14.6)$ \\
Instructors & $n=22$ & $n=3$ & & $n=22$ & $n=5$ \\
Age & $31.9(12.5)$ & $33.3(6.7)$ & & $33.6(12.8)$ & $37.5(15.5)$ \\
Women, \% & 84.6 & 100.0 & & 84.0 & 87.5 \\
Non-Hispanic/white, \% & 60.0 & 71.4 & & 54.2 & 62.5 \\
Experience, y & $13.7(12.1)$ & $9.6(5.3)$ & & $15.5(13.2)$ & $14.5(15.2)$ \\
MVPA, min & $5.3(6.9)$ & $6.9(4.9)$ & & $4.9(6.3)$ & $8.0(5.5)$ \\
\hline
\end{tabular}

Data are presented as mean (SD) or percent unless noted otherwise

Table 5 presents the covariateadjusted means for activity outcomes along with the results from the mixed model linear regressions investigating the differences between private studio classes and community center classes in activity categories. Children in private dance studios were more active with 20.6 minutes spent in MVPA (44.1\% of class time) compared with children in community center classes who had 16 minutes MVPA (34.5\% of class time). Adolescents in private dance studios spent more time in vigorous activity $(6.4 \%$ of class time) compared with adolescents in community center classes $0.8 \%$ of class time).
Figure 1 reveals covariate-adjusted means for minutes of MVPA during dance classes by dance type and age group. Children were more active than adolescents in all dance types except ballet, with a 20.3-minute difference between the least and most active dance type (Latin-F and hip-hop, respectively). There were smaller differences among dance types for adolescents with a 12.6minute MVPA difference between the least and most active dance type (Latin-F and ballet, respectively). The biggest within-dance type difference between age groups was found with partnered dance with children getting 13 more minutes of MVPA compared with adolescents. Within-dance type differences for most other types ranged from 2.4 to 11.1 minutes between children and adolescents.

\section{DISCUSSION}

Objectively measured physical activity during youth dance classes varied dramatically, from 4 to 27 minutes, depending on dance type and age of student. The Centers for Disease Control and Prevention recommends that schools provide 30 of the total 60 minutes of MVPA per day, with after-school activities providing the remaining 30 minutes. $^{3}$ Only $8 \%$ of children and $6 \%$ of adolescents in the current study met these 30-minute guidelines in dance classes. A study using similar methods revealed that from $50 \%$ to $100 \%$ of participants in youth sports practices achieved 30 minutes of MVPA. ${ }^{23}$ Though dance classes have the potential to reduce gender-based disparities in physical activity by appealing mainly to girls, the public health promise of dance classes is not being delivered.

Dance as physical activity in youth is not well studied. Studies to date had small sample sizes, limited age ranges, limited types of dance, and short dance sessions. ${ }^{12-15}$ The current study revealed over twice as much class time in MVPA in ballet

TABLE 5 Relationship of Sedentary, Light, Moderate, Vigorous, and Moderate-to-Vigorous Intensity Physical Activity With Private and Public Dance Classes

\begin{tabular}{|c|c|c|c|c|c|c|c|c|c|c|}
\hline & \multicolumn{5}{|c|}{ Minutes } & \multicolumn{5}{|c|}{ Percent of Class Time } \\
\hline & $\begin{array}{l}\text { Sedentary } \\
(\operatorname{Min})^{\mathrm{a}}\end{array}$ & $\begin{array}{l}\text { Light } \\
(\text { Min })^{a}\end{array}$ & $\begin{array}{c}\text { Moderate } \\
{(\text { Min })^{a}}^{a}\end{array}$ & $\begin{array}{l}\text { Vigorous } \\
\left(_{\text {Min })^{a}}\right.\end{array}$ & $\begin{array}{l}\text { MVPA } \\
(\text { Min })^{a}\end{array}$ & $\begin{array}{l}\text { Sedentary } \\
(\% \text { Time })^{\mathrm{b}}\end{array}$ & $\begin{array}{c}\text { Light } \\
(\% \text { Time })^{b}\end{array}$ & $\begin{array}{l}\text { Moderate } \\
(\% \text { Time })^{\mathrm{b}}\end{array}$ & $\begin{array}{l}\text { Vigorous } \\
(\% \text { Time })^{b}\end{array}$ & $\begin{array}{c}\text { MVPA } \\
(\% \text { Time })^{\mathrm{b}}\end{array}$ \\
\hline \multicolumn{11}{|l|}{ Children } \\
\hline Overall F class type ${ }^{c}$ & 1.85 & 0.05 & 2.10 & 1.07 & $4.29^{\star}$ & 1.95 & 0.18 & 1.73 & 2.52 & $5.05^{\star}$ \\
\hline Private & $12.8(0.9)$ & $14.7(0.8)$ & $15.2(0.8)$ & $5.4(0.7)$ & $20.6(1.1)^{\star}$ & $26.1(1.8)$ & 30.4 (1.5) & $32.4(1.6)$ & $11.6(1.3)$ & $44.1(2.1)^{*}$ \\
\hline Community & $15.2(1.5)$ & $15.2(1.9)$ & $13.0(1.3)$ & $3.4(1.7)$ & 16.1 (1.9) & $31.1(3.0)$ & $32.0(3.4)$ & $28.1(2.7)$ & $6.6(2.7)$ & $34.5(3.6)$ \\
\hline \multicolumn{11}{|l|}{ Adolescents } \\
\hline Overall F class type ${ }^{d}$ & 0.25 & 0.65 & 0.38 & 2.78 & 0.38 & 0.43 & 0.67 & 0.75 & $5.30^{*}$ & 0.06 \\
\hline Private & $16.7(1.5)$ & $23.9(1.2)$ & $9.5(0.9)$ & $3.1(0.7)$ & $12.7(1.4)$ & $30.7(3.0)$ & $44.4(2.3)$ & $18.6(1.8)$ & $6.4(1.2)^{\star}$ & $25.2(2.6)$ \\
\hline Community & $14.9(3.2)$ & $26.0(2.4)$ & $10.7(1.7)$ & $0.7(1.3)$ & $11.0(2.4)$ & $26.2(6.2)$ & $48.6(4.7)$ & $21.8(3.2)$ & $0.8(2.2)$ & $23.8(5.0)$ \\
\hline
\end{tabular}

$P<.05$.

a Analyses adjusted for age, race, class length, BMI percentile, instructor MVPA, community versus private, and clustering within dance classes and instructors.

b Analyses adjusted for age, race, BMI percentile, instructor MVPA, community versus private, and clustering within dance classes and instructors.

c Partnered dance, Latin-F and Latin-SBF were only represented in private studios.

d Partnered dance and Latin-SBF were only represented in private studios. 


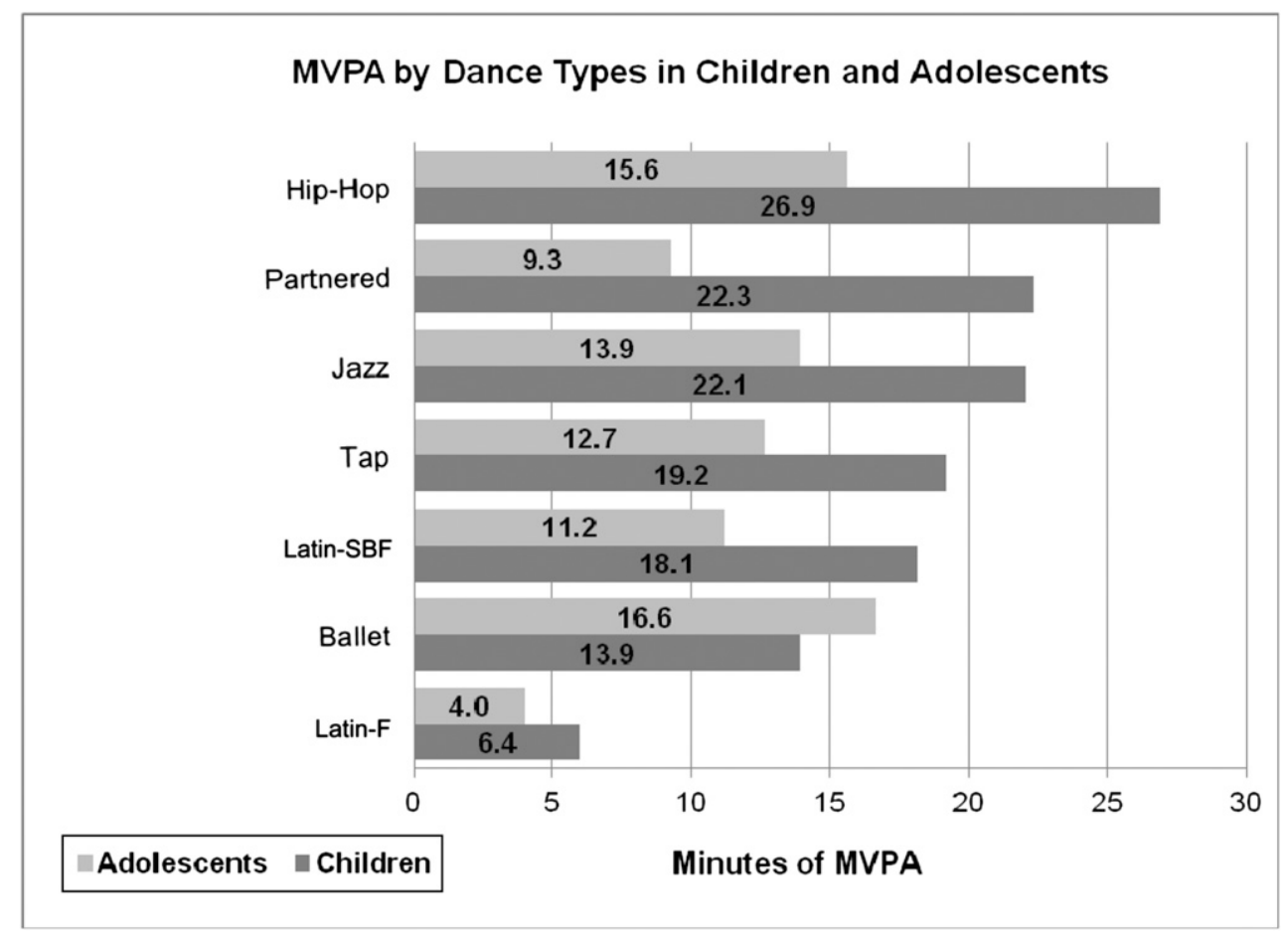

FIGURE 1

Adjusted means for minutes of MVPA during dance classes for children and adolescents. Analyses adjusted for student age, race, class length, BMI percentile, instructor MVPA, community versus private, and clustering within dance classes and instructors.

compared with a previous study using accelerometers, ${ }^{11}$ but differences in epoch length, accelerometer model, and particularly the use of a 3-MET vs 4-MET cut point could explain this difference. ${ }^{17,24}$

Children were more active than adolescents in all types of dance classes, except for ballet. This could be because children are more active in general or because dance classes for adolescents may spend more time teaching routines rather than providing opportunities for active dancing. Lower activity levels for adolescents might also reflect adolescent girls' fear of embarrassment and body consciousness, particularly because dance classes are almost always held in rooms with mirrored walls whereby students are often comparing their movements (and bodies) to one another. ${ }^{25,26}$

Variation by type of dance, specifically in children, was more dramatic than age differences. Latin- $F$ was the least active for both children and adolescents, whereas hip-hop classes were the most active for children and ballet for adolescents, although the differences across dance types were not significant in adolescents. Partnered dancing was an active dance type for children, but not for adolescents, likely reflecting differences in the type of partnered dance. Common partnered dance styles for children were swing and merengue, whereas the common styles for adolescents were traditional ballroom dances. Ballet was a lighter intensity dance type for children but the most active dance for adolescents. This likely reflects more advanced and active jumps and running for the higher-skilled adolescents. The reasons for the large differences in MVPA across dance types among children but not adolescents should be explored in subsequent studies that assess the nature of the dance moves and instructional practices.
It is useful to compare the profile of physical activity of youth dance classes and sports practices, because these are 2 common after-school activity programs. Compared with activity levels in youth soccer and baseball/ softball practices, ${ }^{23}$ dancing was much less active. Though sedentary time was comparable $(30 \%$ of class/practice time), children and adolescents had less vigorous intensity activity in dance compared with soccer (mean $7.2 \%$ vs $28 \%$ of class/practice time, respectively). Some dance types such as jazz, partnered, and hip-hop in children had comparable amounts of vigorous activity compared with baseball/softball $11 \%$ of practice time)..$^{23}$ Vigorous intensity activity is important because it is particularly protective from youth obesity. ${ }^{27}$ Children's dance classes in private studios provided more MVPA (44\% of class time) compared with girls' baseball/softball practices, which spent $\sim 35 \%$ of practice time being active, but less MVPA than girls' soccer (over $50 \%$ of practice time). ${ }^{23}$ 
The current study included some lower-cost dance classes (approximately \$5/class) to allow comparisons with higher-cost private classes (approximately $\$ 17 /$ class). For children, community center classes had less MVPA compared with private classes, whereas for adolescents, community center classes had less vigorous compared with private classes, even after controlling for the higher activity of instructors. It was also notable that community center classes tended to be shorter in duration, have larger class sizes, and have fewer overweight/obese students. It was unexpected that public classes were serving a lower proportion of overweight/obese girls. This finding should be explored in other locations.

Strengths of the study included an objective measure of physical activity, a large sample size from a variety of dance types, age-specific analyses, and multiple classes for each dance type. Limitations included studying dance in only 1 geographic area. Another limitation was height and weight were reported by parents and not objectively measured. Some dance types might not be measured well with accelerometry, particularly styles with extensive upper body movement, such as flamenco. A study of Latin dancing also revealed that accelerometers were not as sensitive as heart rate monitors for measuring physical activity in overweight and obese women. ${ }^{28}$ The current study used 3 METs as the lower limit of moderate-intensity physical activity, though other studies used 4 METs or higher $^{3,29,30}$ reflecting a lack of consensus on definitions. ${ }^{17}$ A 3-MET cut point will result in higher estimates of MVPA compared with higher MET values. However, the US physical activity guidelines are based on 3 METs for all age groups, ${ }^{1}$ which was the rationale for methods used in the current study. The difference in cut points could explain different MVPA levels between the current study and the $0^{\prime}$ Neill et al ${ }^{13}$ study, which used a 4-MET cut point.

\section{CONCLUSIONS}

The current study confirmed findings from the few previous studies that physical activity levels are low in youth dance classes. It appears that most dance classes are substantially less active than youth sports practices, so 1 of the most common types of after-school activity programs is providing youth participants with limited amounts of physical activity. Thus, there is a public health imperative to engage the dance profession in efforts to improve the public health impact of youth dance classes. A fruitful place to begin would be to work with leading dance organizations to adopt public health and physical activity goals. Though there are important social, developmental, cultural, and aesthetics benefits of dance that should be maintained and strengthened, it should be possible to simultaneously increase physical activity. It should be possible to implement more active dance classes in the estimated 32000 private dance studios, ${ }^{11}$ as well as school physical education classes and after-school programs.

Two strategies for increasing physical activity in youth dance classes are suggested by current findings. One strategy is to alter teaching methods to increase physical activity in all dance types. This could be done by using dynamic rather than static warm up periods, having more frequent and longer practice of dance moves, and including a segment of vigorous exercise in each class to improve fitness. A second strategy is to emphasize greater participation in dance class types with higher levels of physical activity. Present results implied that lower-cost dance classes delivered in community centers attracted more adolescents of color who may experience financial barriers to dance classes in private studios. However, public classes tended to be less active. Closer collaboration between public health and dance instruction professionals could lead to changes in dance class practices that could benefit millions of young people, especially girls who are attracted to dance but are much less likely to meet physical activity guidelines. ${ }^{3}$

There are several steps pediatricians and pediatric organizations could take to maximize the health benefits of dance classes. Pediatricians could recommend more active dance types for children interested in dance, such as jazz, hip hop, and partnered types. Local pediatric organizations could compile lists of public and private dance studios and indicate which studios have made commitments or taken steps to ensure relatively high levels of physical activity during dance classes. National pediatric organizations could collaborate with dance instructor organizations to develop guidelines and training opportunities designed to increase physical activity during dance classes.

Address correspondence to Kelli L. Cain, MA, University California San Diego, 3900 5th Ave, Suite 310, San Diego, CA 92103. E-mail: kcain@ucsd.edu

PEDIATRICS (ISSN Numbers: Print, 0031-4005; Online, 1098-4275)

Copyright (C) 2015 by the American Academy of Pediatrics

FINANCIAL DISCLOSURE: The authors have indicated they have no financial relationships relevant to this article to disclose.

FUNDING: No external funding.

POTENTIAL CONFLICT OF INTEREST: The authors have indicated they have no potential conflicts of interest to disclose. 


\section{REFERENCES}

1. US Department of Health and Human Services. Physical activity guidelines for Americans. Washington, DC: US Department of Health and Human Services. Available at: www.health.gov/ paguidelines/guidelines/chapter3.aspx. Accessed April 1, 2015

2. US Department of Health and Human Services. Physical activity guidelines advisory committee report. Available at: www.health.gov/paguidelines/ guidelines/chapter2.aspx. Accessed April 1, 2015

3. Troiano RP, Berrigan D, Dodd KW, Mâsse LC, Tilert T, McDowell M. Physical activity in the United States measured by accelerometer. Med Sci Sports Exerc. 2008;40(1):181-188

4. Centers for Disease Control and Prevention (CDC). School health guidelines to promote healthy eating and physical activity. MMWR Recomm Rep. 2011;60(RR-5):1-76

5. Vilhjalmsson R, Kristjansdottir G. Gender differences in physical activity in older children and adolescents: the central role of organized sport. Soc Sci Med. 2003;56(2):363-374

6. Grieser M, Vu MB, Bedimo-Rung AL, et al Physical activity attitudes, preferences, and practices in African American, Hispanic, and Caucasian girls. Health Educ Behav. 2006;33(1):40-51

7. O'Neill JR, Pate RR, Liese AD. Descriptive epidemiology of dance participation in adolescents. Res Q Exerc Sport. 2011; 82(3):373-380

8. Whitt-Glover MC, Taylor WC, Floyd MF, Yore MM, Yancey AK, Matthews CE. Disparities in physical activity and sedentary behaviors among US children and adolescents: prevalence, correlates, and intervention implications. J Public Health Policy. 2009;30(suppl 1): S309-S334

9. Zhang JG, Ishikawa-Takata K, Yamazaki H, Morita T, Ohta T. Postural stability and physical performance in social dancers Gait Posture. 2008;27(4):697-701

10. Alpert PT. The Health Benefits of Dance. Home Health Care Manage Pract. 2011; 23(2):155-157

11. National Dance Education Organization. Statistics on general education in the United States. National Dance Education Organization. Available at: www.ndeo org/content.aspx?page_id=22\&club_id= $893257 \&$ module_id $=55774$. Accessed June 24, 2014

12. O'Neill JR, Pate RR, Hooker SP. The contribution of dance to daily physical activity among adolescent girls. Int J Behav Nutr Phys Act. 2011;8:87

13. O'Neill JR, Pate RR, Beets MW. Physical activity levels of adolescent girls during dance classes. J Phys Act Health. 2012; 9(3):382-388

14. Nelson L, Evans M, Guess W, Morris M, Olson T, Buckwalter J. Heart rates of elementary physical education students during the dancing classrooms program. Res Q Exerc Sport. 2011;82(2):256-263

15. Huang SY, Hogg J, Zandieh S, Bostwick SB. A ballroom dance classroom program promotes moderate to vigorous physical activity in elementary school children. Am J Health Promot. 2012; 26(3):160-165

16. Kuczmarski RJ, Ogden CL, GrummerStrawn LM, et al. CDC growth charts: United States. Adv Data. 2000;314(314):1-27

17. Cain KL, Sallis JF, Conway TL, Van Dyck D, Calhoon L. Using accelerometers in youth physical activity studies: a review of methods. J Phys Act Health. 2013; 10(3):437-450

18. Welk GJ. Physical Activity Assessments for Health-Related Research. Champaign, IL: Human Kinetics; 2002

19. Freedson P, Pober D, Janz KF. Calibration of accelerometer output for children. Med Sci Sports Exerc. 2005;37(suppl 11): S523-S530
20. Freedson PS, Melanson E, Sirard J. Calibration of the Computer Science and Applications, Inc. accelerometer. Med Sci Sports Exerc. 1998;30(5):777-781

21. Evenson KR, Catellier DJ, Gill K, Ondrak KS, McMurray RG. Calibration of two objective measures of physical activity for children. J Sports Sci. 2008;26(14): 1557-1565

22. Treuth MS, Schmitz K, Catellier DJ, et al Defining accelerometer thresholds for activity intensities in adolescent girls. Med Sci Sports Exerc. 2004;36(7): 1259-1266

23. Leek D, Carlson JA, Cain KL, et al Physical activity during youth sports practices. Arch Pediatr Adolesc Med. 2011;165(4):294-299

24. Vale S, Santos R, Silva P, Soares-Miranda L, Mota J. Preschool children physical activity measurement: importance of epoch length choice. Pediatr Exerc Sci. 2009;21(4):413-420

25. Oliver W. Body Image in the Dance Class $J$ Phys Educ, Recreat Dance. 2008;79(5): 18-41

26. Green J. Somatic authority and the myth of the ideal body in dance education. Dance Res J. 1999;31(2):80-100

27. Gutin B. Child obesity can be reduced with vigorous activity rather than restriction of energy intake. Obesity (Silver Spring). 2008;16(10):2193-2196

28. Lee RE, Mama SK, Medina A, Orlando Edwards R, McNeill L. SALSA: Saving Lives Staying Active to Promote Physical Activity and Healthy Eating. J Obes. 2011; 2011:436509

29. Pate RR, Stevens J, Webber LS, et al. Agerelated change in physical activity in adolescent girls. J Adolesc Health. 2009; 44(3):275-282

30. Mattocks C, Ness A, Deere K, et al. Early life determinants of physical activity in 11 to 12 year olds: cohort study. BMJ. 2008;336(7634):26-29 


\section{Physical Activity in Youth Dance Classes}

Kelli L. Cain, Kavita A. Gavand, Terry L. Conway, Emma Peck, Nicole L. Bracy, Edith Bonilla, Patricia Rincon and James F. Sallis Pediatrics 2015;135;1066; originally published online May 18, 2015; DOI: $10.1542 /$ peds. $2014-2415$

\section{Updated Information \&} Services

References

Subspecialty Collections

Permissions \& Licensing

Reprints including high resolution figures, can be found at: /content/135/6/1066.full.html

This article cites 26 articles, 1 of which can be accessed free at: /content/135/6/1066.full.html\#ref-list-1

This article, along with others on similar topics, appears in the following collection(s):

Sports Medicine/Physical Fitness

/cgi/collection/sports_medicine:physical_fitness_sub

Information about reproducing this article in parts (figures, tables) or in its entirety can be found online at:

/site/misc/Permissions.xhtml

Information about ordering reprints can be found online: /site/misc/reprints.xhtml

PEDIATRICS is the official journal of the American Academy of Pediatrics. A monthly publication, it has been published continuously since 1948. PEDIATRICS is owned, published, and trademarked by the American Academy of Pediatrics, 141 Northwest Point Boulevard, Elk Grove Village, Illinois, 60007. Copyright (C 2015 by the American Academy of Pediatrics. All rights reserved. Print ISSN: 0031-4005. Online ISSN: 1098-4275.

\section{American Academy of Pediatrics}

DEDICATED TO THE HEALTH OF ALL CHILDREN ${ }^{\mathrm{m}}$ 


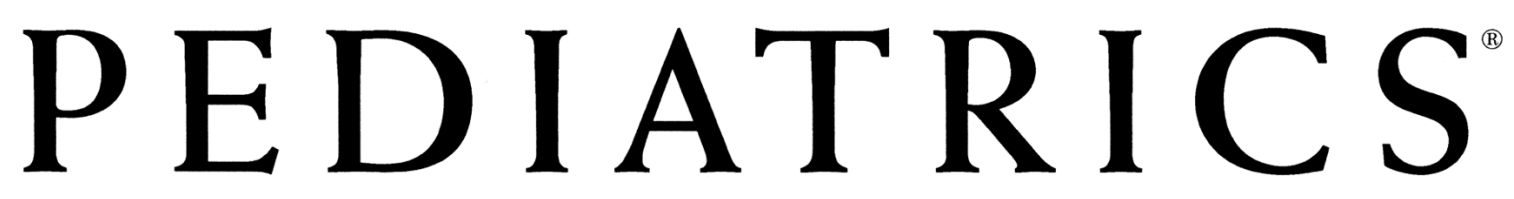

OFFICIAL JOURNAL OF THE AMERICAN ACADEMY OF PEDIATRICS

Physical Activity in Youth Dance Classes

Kelli L. Cain, Kavita A. Gavand, Terry L. Conway, Emma Peck, Nicole L. Bracy, Edith Bonilla, Patricia Rincon and James F. Sallis Pediatrics 2015;135;1066; originally published online May 18, 2015;

DOI: $10.1542 /$ peds.2014-2415

The online version of this article, along with updated information and services, is located on the World Wide Web at:

/content/135/6/1066.full.html

PEDIATRICS is the official journal of the American Academy of Pediatrics. A monthly publication, it has been published continuously since 1948. PEDIATRICS is owned, published, and trademarked by the American Academy of Pediatrics, 141 Northwest Point Boulevard, Elk Grove Village, Illinois, 60007. Copyright (@) 2015 by the American Academy of Pediatrics. All rights reserved. Print ISSN: 0031-4005. Online ISSN: 1098-4275.

\section{American Academy of Pediatrics}

DEDICATED TO THE HEALTH OF ALL CHILDREN ${ }^{m}$ 